\title{
Candidates Sought for Graduate Student Awards at 1990 MRS Spring Meeting
}

The Materials Research Society announces the availability of several awards for graduate students at the 1990 MRS Spring Meeting to be held April 16-21 in San Francisco, California. Each award consists of a $\$ 250$ cash prize, payment of the registration fee for the 1990 Spring Meeting, and a certificate of achievement.

Award selection criteria include the following:

1. Graduate standing in a recognized academic program in materials science, metallurgy, ceramics, or polymers; physics or chemistry, geology or mineral science; electrical, civil, mechanical, mining, or nuclear engineering; or other materialsrelated field.
2. Participation in the 1990 MRS Spring Meeting as an attendee and author or coauthor of a symposium paper.

3. Outstanding performance in the conduct of a thesis project and promise for future substantial achievement in materials research as judged by the faculty adviser.

4. Significant and timely research results.

Graduate student award finalists will be selected prior to the meeting and must participate in the Graduate Student Symposium at the MRS Meeting.to be eligible to receive an award. All finalists will receive a waiver of the meeting registration fee. Award recipients will also each receive $\$ 250$ to be presented during the Plenary Session.
Required application materials include an application form obtainable from MRS headquarters, abstract of the paper to be presented at the meeting, and a letter of support from the research supervisor.

The deadline for applications to be received by MRS headquarters is January 22, 1990. Obtain applications from:

John B. Ballance

Executive Director

Materials Research Society

9800 McKnight Road

Pittsburgh, PA 15237

Telephone (412) 367-3003

Fax (412) 367-4373

1989 MRS Fall Meeting Proceedings

Available at Pre-Publication Prices

Until March 1, 1990

See p. 62

\section{MRS On-Site Short Course Program Reaches Out to Industry}

In 1989 the MRS On-Site Short Course Program continued to provide a valuable educational service to the materials science community by reaching out to discover and respond to industry's special needs. The On-Site Program is designed to take MRS short courses to companies interested in upgrading their staffs' scientific, engineering, and technical knowledge in a cost-effective manner. Several companies now regularly use the MRS On-Site Program for their continuing education programs.

The On-Site Short Course Program was originally developed to respond to companies' needs for training at their own geographical locations. The materials science and technology courses most frequently requested were those a staff member had attended at an MRS meeting and which were considered of interest to the company in general. Companies can take advantage of the convenience and economy of the program when eight or more staff are interested in a particular subject.

In 1989 MRS presented several courses for the Massachusetts Microelectronics Center and also assisted in marketing this local presentation. The program was extremely successful and will probably be expanded and repeated annually for the technical community in that area.

The on-site concept has also been extended to interactions with other professional societies. In a spirit of cooperation and in the interest of establishing communication between respective memberships, MRS presented several courses at the Annual Technical Symposium of the Society of Vacuum Coaters in 1988 and 1989. In 1988 MRS courses enjoyed a successful venue at the World Congress on Superconductivity.

The thrust of this on-going and expand- ing program is to reach out to industries and discover their real needs. New courses are generally developed by MRS to complement symposia topics of high interest to the MRS membership and the materials science community. However, since companies may have needs not already addressed in the existing portfolio of about 55 topics, the MRS Continuing Education Committee solicits suggestions and input from them.

Anyone responsible for continuing education within an organization is invited to contact Vivienne Harwood Mattox, MRS short course manager, to make arrangements to audit portions of any MRS course at an MRS meeting, and to review the course content for applicability. For information about the MRS On-Site Short Course Program, please call Mattox at (505) 294-9532; fax (505) 298-7942. 